ANUARIO DE EstUdios MEDIEVALES

49/2, julio-diciembre de 2019, pp. 793-820

ISSN 0066-5061

https://doi.org/10.3989/aem.2019.49.2.15

\title{
IGLESIA, IMPERIO Y PODER EN EL PRIMER TERCIO DEL SIGLO XIV. EL ENFRENTAMIENTO ENTRE EL PAPADO, LUIS IV DE BAVIERA Y LOS VISCONTI DE MILÁN DESDE LA IGLESIA DE SANTIAGO DE COMPOSTELA
}

\author{
CHURCH, EMPIRE AND POWER IN THE FIRST THIRD OF THE $14^{\text {th }}$ CENTURY. \\ THE CONFRONTATION BETWEEN THE PAPACY, LOUIS IV OF BAVARIA AND \\ THE VISCONTI OF MILAN SEEN FROM THE CHURCH \\ OF SANTIAGO DE COMPOSTELA
}

\author{
Xosé M. SÁNCHEZ SÁNCHEZ \\ Universidade de Vigo \\ https://orcid.org/0000-0002-0779-3336
}

\begin{abstract}
Resumen: El pulso entre Papado e Imperio ha sido una constante en el contexto de la teoría política de la Edad Media. La oposición entre ambos tuvo en los años 20 del siglo XIV un nuevo episodio en el panorama europeo: el enfrentamiento material, doctrinal y político entre Juan XXII y Luis de Baviera, con los Visconti de Milán como peones destacados, y al hilo del cual se empezarán a delimitar las posiciones en la pre-configuración de los Estados Modernos. Este artículo analiza las cuatro comunicaciones relativas a la cuestión que el papa Juan XXII dirige entre 1324 y 1330 al arzobispo de Santiago de Compostela, Berenguel de Landoira, bien próximo al pontífice. Tales fuentes, no localizadas por lo de ahora en otras sedes y de las cuales editamos un documento, permiten desarrollar la incidencia del cambio en la teoría política en el noroeste peninsular así como el seguimiento de la cuestión.
\end{abstract}

Palabras clave: historia medieval; poder político; papado; imperio; Santiago de Compostela; Berenguel de Landoira.

Abstract: The conflict between the Papacy and the Empire was a constant feature in the context of political theory in the Middle Ages. The struggle between them witnessed a new episode in the 1420s: the material, doctrinal and political confrontation between Pope John XXII and Louis VII of Bavaria, with the Visconti of Milan as the main pawns. Following on from this dispute, the positions relating to the preliminary definition of Modern States began to be laid down. This article analyses the four communications related to this issue sent by John XXII between 1324 and 1330 to the archbishop of Santiago de Compostela, Berenguel de Landoira, a man trusted by the pope. These sources, hitherto not located in other sees and of which we publish one document, allow us to study here the impact of the change in political theory in the northwest of the Iberian Peninsula as well as how the question was followed.

Keywords: medieval history; political power; papacy; empire; Santiago de Compostela; Berenguel de Landoira.

\section{SUMARIO}

1. Papado e imperio. Juan XXII y Luis de Baviera.- 2. Papado, imperio y Visconti de Milán desde la iglesia de Santiago de Compostela con Berenguel de Landoira.3. Apéndice documental.- 4. Bibliografía citada.

Citation / Cómo citar este artículo: Sánchez Sánchez, Xosé M. (2019), Iglesia, imperio y poder en el primer tercio del siglo XIV. El enfrentamiento entre el Papado, Luis IV de Baviera y los Visconti de Milán desde la iglesia de Santiago de Compostela, "Anuario de Estudios Medievales" 49/2, pp. 793-820. https://doi.org/10.3989/aem.2019.49.2.15

Copyright: (C) 2019 CSIC. Este es un artículo de acceso abierto distribuido bajo los términos de la licencia de uso y distribución Creative Commons Reconocimiento 4.0 Internacional (CC BY 4.0). 
En el desarrollo político e institucional de la Iglesia de Occidente ${ }^{1}$ a lo largo la Edad Media han sido varios los conflictos y circunstancias que han afectado a sus cimientos más profundos ${ }^{2}$. Si nos centramos en el siglo XIV, lapso crucial en la formulación teórica, destaca como hecho más evidente el traslado de la sede pontificia de Roma a Aviñón, con la centralización eclesiástica y desarrollo administrativo desde la órbita francesa. En segundo lugar, y como proceso en cierta forma derivado de la tensión territorial franco-italiana en el seno de la institución, irrumpe por supuesto el Cisma que dividió a la Iglesia en 1378, activo hasta ya entrado el siglo XV y que antecede a la transición eclesiástica del medievo hacia la modernidad. En el espacio que media entre ambos procesos otra pugna floreció para llegar a todos los rincones, sedes y territorios del continente; un episodio más incardinado en un desarrollo de largo espectro durante todo el período medieval: el enfrentamiento entre el Pontificado y el Sacro Imperio, aquí personado en Juan XXII y Luis de Baviera ${ }^{3}$.

El clamor procedente de los dos bandos con acusaciones, reclamaciones y ataques, llegó tanto a los diversos los reinos europeos como a los respectivos representantes eclesiásticos, sedes obispales y arzobispales. De esta manera fueron recibidas en Santiago de Compostela, uno de los principales centros eclesiásticos de la Península Ibérica, cuatro comunicaciones pontificias acerca del conflicto y su desarrollo ${ }^{4}$. Destaca aquí el carácter privativo de esta documentación, al menos en lo rastreado hasta el presente, e incorporando el matiz de la comunicación y consideración de la cuestión por Juan XXII con uno de sus hombres de confianza en la Península, el dominico

${ }^{1}$ Abreviaturas utilizadas: ACS $=$ Archivo-Biblioteca de la Catedral de Santiago; ASV $=$ Archivio Segreto Vaticano.

${ }^{2}$ Muy adecuada es la recopilación y breve repaso de José Ángel García de Cortázar a los principales puntos calientes de la historia eclesiástica desde el último cuarto del siglo XIII hasta la segunda mitad del XV, poniéndonos ya en perspectiva a la cuestión que ocupa este artículo: "los enfrentamientos entre Bonifacio VIII y Felipe IV de Francia entre 1295 y 1300, el atentado de Anagni en 1303, el traslado de la sede papal a Aviñón en 1309, la extinción de la orden de los Templarios en 1314, las agrias discusiones entre el papa y el emperador Luis de Baviera entre 1326 y 1338, la ostentación mundana de la corte aviñonesa, el cisma de Occidente de 1378 , las dificultades para superarlo y el crecimiento del conciliarismo entre 1407 y 1439, más los fracasos en el empeño por la unión de la Iglesias latina y griega”. García de Cortázar 2012, p. 440. Igualmente Michael Menzel incide en el papel del enfrentamiento con el matiz del camino bajomedieval hacia unas nuevas formas políticas. Menzel 2001.

${ }^{3}$ De manera relativamente general el espacio documental y de fuentes relativo a Luis de Baviera tiene un trabajo colectivo y extendido en el tiempo especialmente destacado en la obra: Acht, Menzel, 1991-2018. Destacan igualmente en cuanto a las comunicaciones con respecto a la curia pontificia: Felten 1998; Miethke 2002.

${ }^{4}$ Múltiples referencias pueden ofrecer la panorámica de documentación compostelana y Pontificado del momento; por sugerir puntos de inicio: la magnífica aportación López 2011, pp. 137-170; o nuestro Sánchez 2013a, pp. 295-306. 
Berenguel de Landoira, prelado compostelano entre 1317 y 1330. Del cuerpo de fuentes que manejamos dos de las comunicaciones, datadas en 15 de julio de 1324, son litterce executoria con dirección concreta y explícita venerabili fratri Berengario, archiepiscopo Compostellano ${ }^{5}$, junto con otras con misma data a los prelados compostelanos en genérico a través del gemipunctus ${ }^{6}$ para transmitir la Sicut ad curam $^{7}$. Siguen, años después, unas últimas litterce con datación de 12 de enero de 1330 en relación a las teorizaciones de Miguel de Cesena sobre la cuestión ${ }^{8}$. Un rastreo de la documentación en los corpus de otras sedes peninsulares no ha devuelto por lo de ahora más copias, casos de Braga ${ }^{9}$, Lugo $^{10}$, Astorga ${ }^{11}$, León ${ }^{12}$, Burgos ${ }^{13}$ o Pamplona ${ }^{14}$, añadiendo una nueva particularidad que nos lleva a incorporar en Apéndice Documental la comunicación más significativa, hasta ahora inédita.

Esta cuestión y sus fuentes documentales nos permitirá examinar el episodio desde el prisma privativo del arzobispado compostelano en la década de los 20 del Trescientos y completar la presencia en lo particular en dicha sede tanto del conflicto entre Iglesia e Imperio en el primer tercio del siglo XIV ${ }^{15}$ como de las nuevas orientaciones que a través de él iba tomando el pensamiento político europeo $^{16}$.

${ }^{5}$ ACS, S 1/4. Copia de su registro en ASV, Reg. Vat. 112, f. 57. Incorporamos transcripción de esta referencia en Apéndice Documental.

${ }^{6} \mathrm{ACS}, \mathrm{S} 1 / 3$.

${ }^{7}$ Monumenta 1909, doc. 944, pp. 779-788.

${ }^{8} \mathrm{ACS}, \mathrm{S} 1 / 5$.

${ }^{9}$ Vasconcelos, Sousa 1986.

${ }^{10}$ Portela 2007.

${ }^{11}$ Cavero, Álvarez, Martín 2001.

${ }^{12}$ Ya sea en la colección catedralicia, en Sáez et al. 1995, como en la diocesana, en Fernández 1978-2006.

${ }^{13}$ Vicario 1998.

${ }^{14}$ Goñi 1965.

${ }^{15} \mathrm{El}$ conflicto vivido en época de Luis de Baviera y la especial atención al proceso electivo, configuración del poder o relación con el pontificado tenían profunda y variada aproximación en Nehlsen, Herman 2002. De manera más general Joseph Lortz nos ofrecía un desarrollo claro en cuanto al enfrentamiento entre Imperio y Papado en el siglo XIV en su Historia de la Iglesia, especialmente a raíz del cambio producido hacia Francia en el epicentro pontificio, desarrollando un epígrafe bajo el título "Última lucha entre el Papado y el Imperio. Nueva concepción del estado independiente". Lortz 2003, pp. 611-614. Y es que "la cruzada y las campañas entonces organizadas para combatir al lado del Rey de Francia contra ambos enemigos [emperador y Visconti], tuvo su eco en Galicia y en toda la Provincia Compostelana”. Díaz 1983, p. 23. Otras obras de tenor monográfico pueden apoyar esas primeras visiones, especialmente: Mollat, Vauchez, 1990.

${ }^{16}$ El contexo y la propia actividad de Luis de Baviera trae consigo la consideración de un espacio nuevo de pensamiento y nuevas bases de asiento del poder político imperial. De manera reciente se realiza compendio de cambios y orientaciones en Seibert 2014. 


\section{PAPADO E IMPERIO. JUAN XXII Y LUIS DE BAVIERA}

Este nuevo episodio de desencuentro entre los poderes temporal y espiritual desarrollado a lo largo principalmente del primer tercio del siglo XIV, así como su afección en la iglesia catedral y arzobispado de Santiago de Compostela en tiempos del prelado francés Berenguel de Landoira, no pueden ser comprendidos en sí mismos, sino que hemos de vincular su análisis a las implicaciones que en dicho contexto tuvo el pontificado de Juan XXII ${ }^{17}$. El cambio de ubicación de la sede pontificia de Roma a Aviñón a inicios de la centuria no trajo consigo únicamente una fluctuación geográfica del eje de influencia de los estados pontificios de Italia hacia Francia. Tendría además como consecuencia una importante y decisiva centralización y desarrollo administrativo y económico de la Iglesia occidental, prefigurando ya, tempranamente, la transición hacia la época Moderna. Ello ha ido acompañado de un fortalecimiento y reafirmación del poder tanto eclesiástico como personal del propio pontífice en el panorama político internacional del siglo XIV, proceso sobre el cual aflora este nuevo episodio. El nuevo espacio burocrático aviñonense, junto con el carácter mercantil de los beneficios eclesiásticos y todo el entramado económico que ahora se desarrolla, son piedra de toque para las críticas a la cabeza de la Iglesia por determinadas personalidades destacadas; unas críticas que Luis de Baviera aprovechará para intentar limitar y reducir la influencia papal sobre el espacio imperial ${ }^{18}$. Igualmente la importancia de tales cuestiones y su aplicación en el espacio peninsular permiten comprender el empeño de Juan XXII en que la prelatura compostelana, por su entidad y extensión en provincia eclesiástica, fuese ocupada por uno de sus hombres de confianza en el panorama político europeo: Berenguel de Landoira, General de los dominicos y nombrado arzobispo de Santiago en 1317. Anterior negociador y legado entre Francia y Flandes, de poco sirven las reticencias que durante meses muestra el recién electo, debiendo emprender el camino y hacerse presente en la sede a mediados de $1318^{19}$.

\footnotetext{
${ }^{17}$ Panorámica general de su papado en Souza 2016, pp. 255-306.

18 "La frecuencia de largos litigios entre aspirantes a un mismo beneficio concedido en expectativa y la abundancia de compras de cargos eclesiásticos, más el inevitable contacto a propósito de los negocios del dinero con compañías mercantiles y bancarias (...) sirvieron de punto de apoyo popular a las críticas de unos pocos intelectuales contra el ambiente palatino y burocrático que adquiría la jefatura de la Iglesia. Ayudados por esas críticas, algunos gobernantes, singularmente el emperador Luis II de Baviera, progresaron en la política de poner coto a las viejas ilusiones papales de dominio en asuntos puramente seculares". García de Cortázar 2012, p. 403.

${ }^{19}$ Cf. Sánchez 2010.
} 
Confluyen en el episodio que nos ocupa dos situaciones geopolíticas nuevas. Por una parte contamos con un papado que mantiene sus reivindicaciones universales pero con su centro de poder en Francia; y por otra triunfa ahora en el Imperio la idea de un poder independiente que mantiene sus pretensiones sobre los territorios italianos en el círculo de influencia pontificia ${ }^{20}$.

El ámbito político en el que se desarrolla este conflicto posee otro antecedente claro y mucho más factual: la sucesión en el título de Rey de Romanos del Sacro Imperio. Cuando en el año 1313 fallece el emperador Enrique VII un cisma se abre en el Imperio al existir dos candidatos postulados para ostentar la dignidad de Rey de Romanos y, de hecho, tres dinastías reales en el estado imperial: Wittelsbacher, Habsburger, Fuxemburger ${ }^{21}$. La coyuntura no fue sencilla: en 1314 es elegido y nombrado Rey Ludwig IV. von Oberbayern -Luis el Bávaro, de Wittelsbach-, hijo del duque Luis II Baviera y Matilde de Habsburgo, pero poco después un grupo de electores descontentos con la designación acusa a Luis de ilegitimidad y elige a Federico el Hermoso de Habsburgo, hijo de Alberto I de Habsburgo ${ }^{22}$.

El interés bávaro por los espacios italianos constituyó desde sus inicios un peligro para el pontífice y el pontificado: en primer lugar por la aproximación imperial y refuerzo gibelino en el entorno de los dominios papales italianos, cerrando un amenazante círculo; y en segundo, vinculado a lo anterior, porque en un momento de reafirmación del poder eclesiástico frente al imperial el papa no podía permitir intromisiones de este tipo. Jacques Duéze, papa como Juan XXII desde 1316, marca su pontificado como uno de los espacios destacados de refuerzo en la autoridad pontificia medieval, recogiendo el testigo de antecesores como Gregorio VII o Inocencio III. Juan XXII llevará a cabo el principal proceso de centralización administrativa en la Iglesia occidental, modelo más tarde para los incipientes estados modernos, así como centralización económica y desarrollo burocrático. En la cuestión que nos ocupa se retoma el punto fuerte que había guiado la evolución eclesiástica desde Inocencio III y a lo largo del siglo XIII: la auctoritas pontificia y la plenitudo potestatis, al menos hasta el pontificado de Bonifacio

\footnotetext{
${ }^{20}$ Lortz 2003, p. 611.

${ }^{21}$ Desarrolla Bernd Schneidmüeller no sólo la situación sino que establece una contextualización general en relación a los conflictos dinásticos relativamente similares al frente de las coronas de Francia e Inglaterra, tras Felipe IV y Eduardo II respectivamente. Schneidmüller 2014, p. 28.

${ }^{22}$ Cf. Büttner 2011. Michel Menzel desarrolla de manera monográfica y reciente la cuestión de la monarquía electiva y el contexto imperial que vive con Luis de Baviera. Menzel, 20152016. De igual manera, otras obras reflexionan acerca del momento en que se encontraba aquí el espacio político. $C f$. Schneidmüller 2013.
} 
VIII que supone un hiato claro. Es en la caída en desgracia de Bonifacio VIII donde debemos ver ya el principio del fin para una doctrina que si bien había dominado el siglo XIII, desde Inocencio III, decae totalmente en el XIV, a pesar de la revitalización que experimenta al hilo del papado de Aviñón, con Clemente V primero y las reformas de Juan XXII después ${ }^{23}$. El poder y la recuperación de la influencia papal al frente de la institución son marcados por la historiografía más reciente como aspectos destacados de su actividad, caso del sintético estudio de Klaus Schatz y el apartado que le dedica al espacio teórico de la monarquía pontificia absoluta desde tiempos de Inocencio IV mediados del siglo XIII ${ }^{24}$. Se opondría ahora el papado a las monarquías premodernas que comenzaban a estar en desarrollo frente a un Imperio que empezaba a perder fuelle en el espacio político europeo ${ }^{25}$.

Así las cosas el pontífice había nombrado a Bertrand de Pouget legado para el norte de Italia en 1319 tratando de reconducir la situación. Igualmente confirma al rey de Nápoles como vicario imperial para el norte de Italia intentando restar poder a Mateo I Visconti, miembro de una de las más destacadas familias nobiliarias y oligarcas de la península italiana ${ }^{26}$, vicario imperial desde el año 1311 y enfrentado al bando güelfo proclive al papado, representado por los Della Torre. No resulta ello poco destacable; el vicariato

${ }^{23}$ Tras el hostigamiento y caída de Bonifacio VIII "la doctrina de la plenitud de poder no muere con el Papa sino que se revitaliza en el periodo en el que la Sede Pontificia se traslada a Aviñón con Clemente V (1305-1314). Será la centralización pontifica junto con la alta burocratización lo que llevará a Juan XXII y Luis de Baviera a un nuevo episodio de enfrentamientos entre poderes". Marín 2005, p. 60.

${ }^{24}$ Schatz 1996, pp. 138-140. El estudio global de K. Schatz desarrolla una buena base para enmarcar ya no sólo la plenitudo potestatis sino su configuración y evolución teórica. Expone por otra parte Armênia Maria de Souza, como uno de los puntos clave, "su concepción del papado como el gobierno supremo, por encima del Imperio, y su perseverancia en realizar efectivamente la doctrina de la plenitudo potestatis, que Bonifacio VIII había explicitado sin ser capaz de imponerla". Souza 2016, p. 256.

${ }^{25}$ Ana Paula Tavares Magalhães cifra como caso modelo de este cambio la oposición que vivirá el papado con el rey de Francia, y retoma la opinión, bastante ilustrativa, de Marcel Pacaut: "a luta, que então confrontava o papa não mais com o imperador, mas com o rei da França, era representativa do declínio da instituição imperial e do fortalecimento dos Estados". Tavares 2008, p. 225.

26 "Ousted by a rebellion of the former ruling family, the della Torre, Matteo had returned to rule again in 1311 as imperial vicar general of Milan and its territories; on the death of Henry VII in 1313, the General Council of Milan appointed him signore (dominus et rector generalis) of the city”. Black 2009, p. 38. Acerca de los Visconti, una aproximación reciente: Filippini 2014. En el marco del desarrollo milanés en relación con el contexto político peninsular podemos considerar la perspectiva de estudios como Cabezuelo 2006, pp. 253-294.

Los Visconti construían ahora su fortaleza linajística, con especial presencia a lo largo del siglo XIV de referencia a las figuras destacadas de la familia como eran el propio Mateo I Visconti o el fundador Ottone, fallecido en 1295; "intendono sottolineare l'appartenenza a una stirpe che proprio allora stava costruendosi le credenziali di un glorioso passato". Monti 2016, p. 10. 
imperial es señalado como una de las vías empleadas por los Visconti para asentar su poder político y militar sobre el espacio urbano, junto a la elección episcopal y el dominio de los cargos comunales ${ }^{27}$. Se desarrolla en este contexto, ya en el año 1320, la acusación papal hacia Mateo Visconti por herejía y brujería, siguiendo la acusación del clérigo milanés Bartolomeo Cagnolato $^{28}$.

A partir de este momento el enfrentamiento entre Visconti y papado fue abierto y militar, sobrepasando el momento de Mateo I, que fallece en 1321 , convicto ya por brujería. En septiembre de 1322, y gracias a las tropas suizas, Luis derrota a Federico en la batalla de Mühldorf, con la consiguiente renuncia del Habsburgo en su reclamación al trono ${ }^{29}$. El partido gibelino tenía ya un primer espada y en 1323 la Dieta convocada en Nuremberg ensalza al vencedor y pone fin al período de incertidumbre.

La formulación del poder laico tomaba aquí, recogiendo una tradición desde mediados del siglo XIII, reflejos en la ideología que regía el pontificado: la plenitudo potestatis aparece desde mediados del Doscientos en el espacio teórico imperial (principalmente con Federico II) siguiendo una difusión e influencia que abarcaría buena parte de los reinos europeos ${ }^{30}$ y con continuación en las reflexiones teóricas de autores como Juan de París, que establece las tipologías de regnum y sacerdotium ${ }^{31}$. En el caso peninsular, Javier Fernández Conde introducía ya las nuevas formas de pensamiento y formulación teórica de la política laica y realeza desde el reinado de Alfonso X; durante la baja Edad Media, y si bien autores con planteamientos políticos seculares no se tenían en cuenta todavía en la historia del pensamiento político peninsular ${ }^{32}$, como eran Guillermo de Ockham o Marsilio de Padua, sí entramos una teoría política diferente y de corte naturalista y corporativista.

A partir de este momento los acontecimientos se desencadenaron definitivamente y el conflicto con el papado se hizo evidente ya en hechos. Luis, ya Luis IV de Baviera y ejerciendo como Rey de Romanos, comienza a ejecutar sus derechos sobre los territorios situados en el norte de Italia, para lo cual toma como primera medida el nombramiento de un legado para dicho espacio geográfico confiando en los Visconti de Milán. En su ascensión Luis había

${ }^{27}$ Cariboni 2008,p. 7. Se define aquí la fórmula vicarial y el uso dado por los Visconti, en medio de un extenso análisis sobre la política milanesa de la baja Edad Media.

${ }^{28}$ Acerca de la vertiente más política de este proceso: Liere 2001,pp. 169 ss.

${ }^{29}$ Varias obras nos ofrecen un marco adecuado: Wilhelm 1927; Patera 1992; Lortz 2003, pp. 599 ss.; Chélini 2006, pp. 489-490.

30 "The dissemination of plenitude of power to other European monarchs soon followed its use by the emperor, though precise dates are hard to come by". Black 2009, p. 36 .

${ }^{31}$ Bertelloni 2006, pp. 51-66.

${ }^{32}$ Fernández 2011, pp. 116-117. 
contado con el apoyo de las ciudades gibelinas del norte italiano, caso de Milán o Verona, desde hacía tiempo enfrentadas al poder pontificio y destacando especialmente el apoyo prestado por Mateo I Visconti. Sobre esta base, un año después de la victoria del bávaro, Juan XXII convoca al emperador en octubre de 1323 bajo la acusación de haber ayudado a los Visconti, que habían sido declarados herejes en $1318^{33}$, reclamándole además que cejase en su empeño por titularse Rey de Romanos bajo pena de entredicho. Una disposición que resultó completamente ineficaz y a la que sigue la excomunión.

Como respuesta, en 1324 Luis de Baviera expone en el denominado Manifiesto de Sachsenhaüsen sus profundas críticas al abuso de poder pontificio en cuanto a las censuras eclesiásticas y a sus acciones contra el emperador, en una clara muestra de la oposición teórica entre las autoridades pontificia e imperial. El emperador denuncia en el manifiesto, que toma forma de apelación extraiudicialis, una supuesta elección ilegal de Juan XXII y solicita la reunión de un Concilio general como representante de la Iglesia ${ }^{34}$. La reacción del papa fue nuevamente rauda con una nueva excomunión y emitiendo una sentencia de entredicho para él y sus seguidores ${ }^{35}$.

Luis de Baviera lejos de contenerse se corona el 31 de mayo del año 1327 rey de Italia en Milán, en la catedral de San Ambrosio, ciñéndose la Corona Férrea de los Lombardos ${ }^{36}$. Marcha sobre Roma al frente de su ejército y al año siguiente en 1328 será ya coronado emperador por Sciarra Colonna en Roma y en nombre del pueblo romano ${ }^{37}$. Con todo ello el conflicto ascendió otro peldaño y en ese año Luis emite el decreto Cunctos populos por el que depone a Juan XXII acusándole de herejía para promover poco después al franciscano Pietro Rainalduccio da Corvara como nuevo papa, que toma el nombre de Nicolás $\mathrm{V}$ y será coronado en ese mismo año por el propio emperador $^{38}$. Señala Jean Chélini que no resulta nueva esta técnica en las pugnas de los Hohenstauffen con el papado aunque como puntualiza Bernd Schneidmüller se reinventan ahora la tradición y las formas ceremoniales destacando ein typisches Indiz für die Uneinheitlichkeit einer vormodernen Institution ${ }^{39}$,

\footnotetext{
${ }^{33}$ Las excomuniones no afectan únicamente a Milán, sino también a los gibelinos de Mantua y Verona. Poco después, en 1320, se abre un proceso a Mateo I Visconti, en Aviñón, acusándole de intentar asesinar al papa por medios nigromantes.

${ }^{34} \mathrm{Cf}$. Böttcher 2010 .

${ }^{35}$ Ullman 1999, p. 291.

${ }^{36}$ Acerca no sólo de esta coronación sino del espacio simbólico en la construcción política desde la Corona Férrea de los lombardos y el tesoro de Teodelinda $c f$. Majocci 2010.

${ }^{37}$ En relación al itinerario y actividad de Luis en Italia $c f$. Berg 1987.

${ }^{38}$ Lortz 2003, p. 612. Acerca del decreto destaca el reciente estudio Souza, J.A. 2016, pp. 307-350.

${ }^{39}$ Schneidmüller 2014, p. 29.
} 
en una atención especialmente destacada del proceso en lo formal y en el cambiante marco de la teoría política en que se inserta. En este caso la ofensiva teórica se había iniciado ya anteriormente, materializada en la obra de Marsilio de Padua y Jean Jandun de 1324 Defensor pacis ${ }^{40}$, que trasciende en importancia a esta cuestión imperial por lo que tiene de orientación en la evolución política de los estados modernos ${ }^{41}$. La deriva de lo religioso se entremezcló con ideología y política, en un espacio de cambio y evolución que mudaría Europa lenta pero inexorablemente; la actividad de personajes dentro de la propia Iglesia como Marquard von Randeck da buena cuenta ${ }^{42}$. García de Cortázar clarifica la encrucijada:

las hostilidades entre Sacerdotium e Imperium se reabrieron y lo hicieron en un contexto político, doctrinal y religioso que, sin ser radicalmente novedoso, se complicó enseguida tanto por el fortalecimiento teórico y práctico de las monarquías como por el estallido del conflicto de los Cien Años entre Francia e Inglaterra ${ }^{43}$.

De hecho, ese año 1328 marca la basculación en las formulaciones de Guillermo de Ockham de un espacio filosófico a otro de crítica política ${ }^{44}$, dando lugar a obras y reflexiones que pondrán algunas de las bases del pensamiento civil bajomedieval ${ }^{45}$.

Y es que el entramado filosófico-ideológico de la cuestión, así como los espacios de pensamiento que genera, resultan profundamente interesantes, dando lugar a otra controversia de consecuencias rotundas no sólo en el marco del pensamiento sino en el de la evolución política de los territorios europeos; otro enfrentamiento a nivel intelectual siquiera más peligroso para la autoridad pontificia: el escepticismo con respecto a la plenitudo potestatis ${ }^{46}$

\footnotetext{
${ }^{40}$ José Ángel García de Cortázar pone de manifiesto la delicada situación en que esta obra es presentada, con una Orden franciscana asumiendo los presupuestos de los espirituales, Miguel de Césena depuesto y la reclamación de explicaciones a Guillermo de Ockham. García de Cortázar 2012, p. 409.

${ }^{41}$ Define Chèlini el Defensor pacis como un "manifeste agressif pour une totale laïcisation du pouvoir politique" y desarrolla un breve análisis de la obra en Chèlini 2006, pp. 490-492. Acerca de las posturas de Marsilio de Padua, ver Marín 2005, pp. 58 ss.

${ }^{42}$ Una actividad que tiene su inicio en el conflicto con Juan XXII y la oposición en cuanto a los Visconti. Eisenzimmer 2011, pp. 268-270.

${ }^{43}$ García de Cortázar 2012, p. 409.

${ }^{44}$ Tavares 2008, p. 250.

${ }^{45}$ Las implicaciones y aplicaciones de este desarrollo en el marco del pensamiento son variadas y de amplia afección en el marcan del derecho civil dentro del espacio imperial primero, europeo después. Sirva como muestra la aportación de Herman Nehlsen relativa al derecho matrimonial en el Tirol en Nehlsen, Herman 2002, pp. 285-328, o su aplicación al derecho urbano en Eckhardt 2007.

${ }^{46}$ Marín 2005, p. 58.
} 
e igualmente la asunción y difusión del concepto desde los presupuestos del poder laico, en el caso que nos ocupa especialmente en la vida política de Milán en formulaciones que navegan entre la reafirmación política y el espacio simbólico del poder urbano ${ }^{47}$.

Si bien la emisión y comunicación de las admoniciones, entredichos y excomuniones es más importante de lo que puede parecer, ya que implica la oficialización de las condenas, en el contexto del conflicto con Luis de Baviera planteó un problema, extensible a la actitud eclesiástica de este momento: la excesiva utilización de estos medios. Son tales sanciones, teóricas y prácticas, las que dan origen a las litterce recibidas en la sede de Santiago de Compostela durante la prelatura de Berenguel de Landoira y las que nos acercan a una perspectiva ibérica y noroccidental de la cuestión. De hecho a nivel peninsular el conflicto entre poderes se deja ver en algunas de las actuaciones posteriores de la monarquía castellana hacia el pontificado, caso de Alfonso XI y la embajada enviada ante Benedicto XII tras la victoria de Tarifa en 1340 , concebida no como un simple acto de comunicación al pontífice, sino como una oportunidad para desplegar la propaganda política que le interesaba al Rey castellano ${ }^{48}$. Un proceso que no hace sino recoger todo lo que se había sembrado desde el desarrollo político y teórico del primer tercio de la centuria.

\section{PAPADO, IMPERIO Y VISCONTI DE MILÁN DESDE LA IGLESIA DE SANTIAGo DE COMPostela CON BERENGUEl DE LANDOIRA}

La presencia y actividad pontificia en la Península Ibérica durante el pontificado de Juan XXII tenía ya un destacado precedente en la estancia y periplo del legado a latere Guillermo de Peyre Godin, que había recorrido los territorios peninsulares y diversas sedes y centros entre 1320 y 1323 ; asiste aquí al Concilio de Valladolid, del que parten luego otros como el concilio provincial compostelano convocado por Berenguel en noviembre de 1324 y donde quizá se diesen a conocer las primeras comunicaciones pontificias compostelanas tocantes a Luis de Baviera y los Visconti de Milán. Cierto que el tenor de la presencia del legado había respondido, principalmente, a la reforma y centralización económica que Jacques Duéze estaba desarrollando al

\footnotetext{
47 “'In numerosi documenti per dare forza all' azione giuridica furono così inserite espressioni indebite quali «plenitudo potestatis» e «ex certa scientia», che indicavano attributi e prerogative proprie soltanto". Cariboni 2008, p. 32.

${ }^{48}$ Rodríguez-Picavea 2010, p. 767.
} 
frente de la Iglesia, así como a la mediación en la tutoría del reino castellano ${ }^{49}$, pero ambos ámbitos, monetario y político-doctrinal, se entrecruzan cuando en 1325 el Papa solicita una exacción para sufragar el enfrentamiento con el emperador (pagada por las distintas sedes -cuando se hacía- a regañadientes) ${ }^{50}$.

El pontífice remite a todas las sedes obispales y arzobispales comunicaciones de condena y excomunión a Luis de Baviera. Las littera executoria que se reciben en Santiago de Compostela, fechadas en 15 de julio de 1324, recogen los fundamentos del conflicto. Desde un punto de vista historiográfico las referencias a estas fuentes, más allá de los catálogos compostelanos, se remontan a lo poco que les dedica Antonio López Ferreiro en su Historia de la Santa AM Iglesia de Santiago y a la recopilación de documentos pontificios que anota José Guerra Campos en varias informaciones manuscritas y custodiadas en su colección personal, desde hace un tiempo depositada en el Archivo-Biblioteca de la Catedral de Santiago ${ }^{51}$.

En su primera comunicación Juan XXII ordena a los prelados de Santiago, en una directio con gemipunctus, que Luis de Baviera no sea reconocido como Rey de Romanos en tanto la Santa Sede no emitiese un juicio, afirmando que el candidato debía de obtener el reconocimiento pontificio, lo cual no se había producido todavía ${ }^{52}$. No sólo eso sino que prescindiendo de dicha aceptación Luis se estaba intitulando ya como tal, con una asunción de poderes que el pontífice no estaba dispuesto a permitir. El proceso de refuerzo de la autoridad pontificia y del poder eclesiástico que estaba llevando a cabo Juan XXII se vería profundamente afectado y en entredicho si no se conseguía limitar el desmán bávaro, su actividad italiana y la ignorancia sobre la propia auctoritas; y en este contexto la acción sobre las sedes, brazo ejecutor principal, resultaba primordial.

De estas comunicaciones no podemos registrar testimonio en otros centros peninsulares aunque sí hay intercambio epistolar relativo a la cuestión. Por examinar un caso próximo al de Compostela, en la sede de Braga de las litterce de 15 de julio conservamos la Quam graviter, pero no la Propter excessus que inserta la Sicut ad curam; sí cuenta la sede portuguesa sin embargo con otras comunicaciones admonitorias anteriores a las compostelanas, de los días 4 y 9 de mayo ${ }^{53}$. La información a las sedes arzobispales parece ser clave, cabeza en la distribución administrativa diocesana que ahora se de-

\footnotetext{
${ }^{49}$ Testimonio de primera mano en cuanto a su actividad y relación con la monarquía a su llegada la tenemos en la Crónica de Alfonso XI. Cerdá 1787, cap. XVI, pp. 36-37.

${ }^{50}$ Ver Rucquoi 1991,pp. 99-122, especialmente, p. 118.

${ }^{51}$ ACS, C 21/1. Ref. en Novás 2008, n 23-1, p. 35 y Sánchez, Novás 2013, nº 23-1, p. 337

${ }^{52} \mathrm{ACS}, \mathrm{S} 1 / 3$. Se comunica y traslada aquí la Sicut ad curam.

${ }^{53}$ Vasconcelos, Sousa 1986, pp. 89-90.
} 
sarrollaba, pues no ocurre lo mismo con los obispados del noroeste ${ }^{54}$. Igualmente la comunicación directa y nominal con Berenguel de Landoira en el caso compostelano añade un nuevo matiz en la gestión de la cuestión pues la figura del prelado destaca en el marco peninsular no sólo por su cargo en una de las sedes principales sino por el cariz de proximidad que lo unía con Juan XXII, hombre confianza ya anteriormente para las negociaciones políticas de Francia y Flandes y ahora para la gestión de asuntos como la cruzada contra los rebeldes.

En Santiago de Compostela había varias razones para seguir las indicaciones y disposiciones papales. En primer lugar, y como resulta evidente, por la propia jerarquía eclesiástica, inclusa en un proceso de refuerzo de la autoridad del Papa al frente de la Iglesia Occidental. Pero además otra situación vinculaba Compostela con Aviñón de manera más estrecha y bien relacionada con las fuentes que documentamos: el contexto político en que había desembarcado Berenguel de Landoira a su llegada en 1318, casi un año después de su nombramiento. A la par que se enfrentan poder laico y eclesiástico a nivel europeo, en la ciudad de Santiago de Compostela se libraba igualmente un choque entre ambos, en este caso por la jurisdicción de la urbe. La ciudad compostelana experimenta a lo largo de los siglos medievales varios episodios de enfrentamiento entre unos poderes urbanos que intentaban sustraer el señorío eclesiástico para ponerlo bajo autoridad regia y la iglesia de Santiago que buscaba retenerlo bajo su potestad. Desde el siglo XII, con Diego Gelmírez, el tira y afloja entre ambos bandos es recurrente ${ }^{55}$, y ya desde el XIII vive la ciudad un largo período realengo en 1266-1311 hasta su devolución al señorío eclesiástico por Fernando IV. El conflicto y las reclamaciones afloran una vez más tras el fallecimiento del arzobispo Rodrigo de Padrón en 1316 y una convulsa sede vacante sin acuerdos para la sucesión, materializadas en una revuelta urbana ${ }^{56}$.

Mientras el cabildo se encuentra dividido ante la elección de nuevo prelado, la ciudad, liderada por Alonso Suárez de Deza al frente de la burguesía, se levanta en armas y porfía nuevamente por sustraer la jurisdicción. Buscando solución expeditiva a esta cuestión Juan XXII nombra arzobispo en 1317 a Berenguel, a la sazón general de la Orden de los Dominicos. Y no sólo eso, sino que al año siguiente pone a su servicio una serie de medidas orientadas al fortalecimiento de la posición arzobispal en Compostela: conce-

\footnotetext{
${ }^{54}$ Hemos señalado ya los casos de Lugo o Astorga u otros más lejanos como León, Burgos o Pamplona. Ut supra.

${ }_{55}^{55}$ Una cuestión ampliamente analizada en Portela, Pallares 2000, pp. 107-131.

${ }^{56} \mathrm{Hemos}$ considerado ya este caso concreto desde una perspectiva de la relación con el pontificado en Sánchez 2008, pp. 195-208.
} 
de un indulto para asumir el palio sin ser consagrado; permite la percepción de rentas de la provincia eclesiástica; y otorga la facultad para absolver de sentencias de excomunión ${ }^{57}$.

La resolución del conflicto tarda algo en llegar y es en el año 1320 cuando, con el ajusticiamiento de Alonso Suárez y sus partidarios en el castillo de Rocha Forte, la situación vuelve a su cauce y la jurisdicción compostelana se consolida en manos eclesiásticas. Berenguel se confirma aquí como uno de los hombres de confianza de Juan XXII en la Península ${ }^{58}$ mientras este episodio trae ecos, mutatis mutandis ${ }^{59}$, del enfrentamiento entre poderes laico y eclesiástico que se estaba desarrollando en un marco más general ${ }^{60}$.

Mientras esto ocurre, a nivel europeo Luis de Baviera, tras la muerte de Mateo I, apoyó directamente a los hijos de éste, Raynaldo y Opizo Visconti de Milán, que mantuvieron abierto el enfrentamiento con el papado buscando la expansión de su propio dominio. El conflicto güelfo-gibelino se recrudecía; Juan XXII habría pretendido aprovechar la pugna y doble candidatura al trono del Rey de Romanos para reforzar el dominio güelfo en el norte de Italia, algo a lo que reaccionaron enérgicamente los gibelinos, especialmente Milán, con los Visconti, y Verona, con los Della Scala.

Este apoyo pasó factura a los Visconti, que junto con Luis, recibieron rauda y enérgica condena pontificia; en 1320 Juan XXII había excomulgado a Mateo I Visconti y a otros señores gibelinos, con las usuales acusaciones de herejía, anexión de propiedades eclesiásticas... Si bien se podría pensar que en nada había afectado esta "cotidiana" medida al poder temporal, los habitantes de la ciudad de Milán se vieron incluidos en el interdicto, haciendo tambalear la confianza en sus propios gobernantes ${ }^{61}$. Poco después, en marzo

${ }^{57}$ Ibidem, p. 202.

${ }^{58}$ Ibidem, p. 204.

${ }^{59}$ Cierto es que el caso compostelano otros factores entraban a jugar su papel, como la postura de la monarquía, en un principio relativamente neutral y que pasa a apoyar a Berenguel desde 1319 o los propios factores urbanos y de desarrollo económico de una ciudad en claro despegue en el marco de un sistema feudal que empezaba a necesitar de francos retoques. Ibidem, p. 203.

${ }^{60}$ Antonio López Ferreiro hace extensible el contexto de enfrentamiento entre las dos principales esferas de poder del mundo medieval a otros conflictos del reino de Galicia como la revuelta de los burgueses de Lugo en tiempos de Fernando IV. López, t. VI, p. 80.

${ }^{61}$ Black 2009, pp. 38-39. El estudio de las varias consecuencias y afecciones del interdicto ha dado lugar a aproximaciones particulares, $c f$. Bauer 2005. De hecho de cara al futuro no continuó por buen camino la relación de Visconti e Imperio, con altibajos jalonando el itinerario. En 1327, luego de la muerte en extrañas circunstancias de Stefano Visconti, los principales miembros de la familia son encarcelados por el emperador, devolviéndoles al cabo de un año una república de Milán descontenta con su gobierno y en franca suspicacia tras guerras, férrea mano imperial, impuestos, excomuniones y entredichos. El momento es delicado igualmente para la república lombarda en cuanto a la configuración del poder urbano. El asentamiento de los Visconti en el espacio del poder ciudadano bascula entre 
de 1323, y ya con Galeazzo I Visconti como capitanus et dominus desde el año anterior -de hecho había derrotado a las fuerzas papales en Basignanael papa emite una nueva excomunión que se recibe en medio de cierta agitación en la república milanesa ${ }^{62}$. Las litterce executorice que se dirigen a Compostela 15 en julio de 1324 e insertan la Sicut ad curam de 11 de junio son las que recogen estos principios contra

omnes etiam illos et singulos qui confederationes, pactiones et societates huiusmodi dicto electo contra processus huiusmodi post dictum terminum presumerent observare, predictas penas et sententias incurrere voluimus ipso facto contra eos gravius spiritualiter et temporaliter processuri prout nobis expediens videretur ${ }^{63}$.

En el texto compostelano de 1324 el papa explicita además una advertencia que no por usual resulta menos válida: cualquier rey, reino o imperio que se adhiriese a la causa bávara vería caer sobre ellos las penas de excomunión ${ }^{64}$. Para completar el panorama, estas admoniciones no se circunscriben al ámbito espiritual, con interdictos y excomuniones sino que fueron ampliadas a la amenaza de retirar los privilegios y feudos que se pudiesen obtener ${ }^{65}$.

Ese mismo 15 de julio de 1324 Juan XXII remite una nueva comunicación con dirección particular a Berenguel de Landoira ${ }^{66}$ disponiendo que convocase en una reunión a todos los abades, obispos, priores y cabildos de Galicia en la cual se leyesen públicamente las sentencias emitidas contra sus opositores milaneses ${ }^{67}$. Se mencionan bien a las claras los destinatarios: Ga-

los intentos de sucesión hereditaria e inserción en la tradición urbana de consejos como el Ottocento, y la imposición, en época de Luchino y Giovanni, de una nueva curia de jueces y vicarios que se sobreponen, o lo intentan, al ya existente consejo de juristas de Milán. Cf. Cariboni 2008, p. 18.

${ }^{62}$ Black 2009, p. 39.

${ }^{63}$ Esos "Mediolanensium rebellium". ACS, S1/3.

64 "Et quia si deinceps prefatus Ludovicus se Regem Romanus seu electum intitulare presumeret, seu administrationi Regni uel Imperii ingerere atemptaret, eius excessus et contumacia graviores existerent quam ante nostram prefatam sententiam extitisent [...] per hoc nostrum edictum publicum monemus eidem nichilominus auctoritate apostolica districtius iniungentes sub penis excommunicationis et privationis feudorum que ab Ecclesia Romana vel aliis seu Imperio obtinet". ACS, S1/3.

65 "Sub penis excommunicationis et privationis feudorum que ab Ecclesia Romana vel aliis seu Imperio obtinet". ACS, S1/3.

${ }^{66}$ Para López Ferreiro ambas comisiones son muestra, de la confianza y estima que Juan XXII tenía en Berenguel, aunque realmente poco espacio dedica al asunto más que una referencia a la presencia de los documentos. López 1903, pp. 79-80. José Guerra Campos resume el contenido de esta última como "Publicación herejía y rebeldía de los hijos de Mateo de los Vizcondes herejes de Milán". ACS, C 12/1.

67 "Per apostolica scripta mandamus quatinus predictos episcopos electos, abbates, priores, decanos, prepositos, capitula, conventus et alias personas ecclesiasticas totius regni Galecie 
leazzo I Visconti, señor de Milán en 1322-1327; Marco Visconti; Luchino Visconti, señor luego de Milán en 1339-1349; Giovanni Visconti; Stefano Visconti, señor de Arona; Mateo I Visconti, el Grande; Rinaldo d'Este, señor de Ferrara; y su hermano Obizzo III d'Este, marqués de Ferrara desde $1317^{68}$. La convocatoria debía hacerse a los eclesiásticos del reino fuesen o no de su provincia eclesiástica ${ }^{69}$, una precisión que no es gratuita. Su explicación remite al hecho de que el mapa diocesano contravenía el político desde la configuración de las diócesis compostelana y bracarense en el siglo XII, de manera que la provincia eclesiástica compostelana se extendía por territorio portugués mientras que las sedes gallegas dependían de $\mathrm{Braga}^{70}$.

Sobre esta base podemos suponer cierta relación en la recepción de este documento con la celebración del concilio provincial compostelano el lunes 12 de noviembre de aquel mismo 1324 presidido por Berenguel. Emanan de este unas constituciones provinciales ${ }^{71} \sin$ referencia alguna explícita a la situación general aunque varios de sus cánones y acuerdos nos remiten al mismo fondo, como §VIII. De violatoribus et spoliatoribus ecclesiarum o el posterior $\$ X I I I$. De violatoribus immunitatis et iuribus clericorum $^{72}$. El contexto de la reciente revuelta compostelana de 1318-1320 no era ajeno a estas disposiciones igual que tampoco lo debía de ser la situación europea, conocida a través de las recientes litterce. Debió de ser aquí de hecho donde se dio a conocer la cuestión y las letras apostólicas a los representantes provinciales, cumpliendo el mandato pontificio.

En esas mismas litterce executorice el Papa ahonda en la necesidad de recaudación y consecución de fondos para la empresa contra los milaneses, dejando sentir en el noroeste peninsular la cuestión económica además de la política. El papa precisaba recursos monetarios y materiales para desarrollar las campañas contra Luis y los Visconti ${ }^{73}$ de manera que en la tercera de

quamvis de tua non sint provincia necnon tuorum civitatis, diocesis et provincie que tamen de regno Portugalie non existant, de quibus tibi videbitur expedire, ad certos (...) et locum, auctoritate nostra comictare procures processos nostros, presertim dictas remissiones et indulgencias et alia contenta in (...) publicaturus solemniter, ac iniurias, excessus, contumelias et horrenda scelera per eosdem hereticos eorumque complices". ACS, S1/4.

68 "Heretici Galeatius, Marchus, Luchinus, Iohannes et Stephanus, nati dampnate memorie quondam Mathei de Vicecomitibus, heretici de Mediolano, necnon Raynaldus et Opizo". ACS, $\mathrm{S} 1 / 4$.

69 "Totius regni Gallecie licet de tua non sint provincia". ACS, S1/4.

${ }^{70}$ Sánchez 2013b. No será hasta la finalización del Cisma de Occidente que se ponga una solución a la cuestión.

${ }^{71} C f$. Justo 2001, pp. 344-355.

${ }^{72}$ López, t. VI, ap. IX, pp. 39 ss. Justo 2001, p. 349.

73 "Muy en el radio de la política aviñonense estaba también la colaboración económica para las campañas pontificias contra los Visconti milaneses y contra el rebelde emperador Luis el Bávaro”. Díaz 1983, p. 23. 
las comunicaciones de $1324^{74}$ el arzobispo compostelano recibe el mandato de recaudación en el territorio y principalmente se le solicita en palabras de Díaz y Díaz ser el animador del subsidio que para esta finalidad se imponía a las Iglesias del reino de Castilla ${ }^{75}$. En este sentido José García Oro, recogiendo estudios de Goñi Gaztambide, señala que a pesar de dedicarse de inmediato a la cuestión el pontífice encontró suerte dispar en el reino: encontró prontitud en el orensano Gonzalo Núñez de Noboa y reticencias en el obispo de Lugo, Juan ${ }^{76}$.

Pero como hemos remarcado la disputa no originó únicamente -que no hubiese sido poco- un enfrentamiento político con todo lo que de él devenía. Se entrecruzan aquí posiciones a medias entre teología y pensamiento político componiendo igualmente dos espacios de reflexión en torno a los bandos papal e imperial ${ }^{77}$ y dotando a la cuestión de una importancia capital en lo que tiene de avance de las concepciones políticas de la modernidad y pre-configuración de los estados modernos. Este proceso permite contextualizar la comunicación que se remite a la iglesia de Santiago con fecha de 12 de enero de 1330. En ella Juan XXII se pone en contacto con el arzobispo compostelano, todavía Berenguel, para comunicarle los errores en que había incurrido el teólogo Miguel de Cesena, Ministro General de la Orden franciscana y apoyo en el bando de Luis de Baviera, pidiéndole además que los haga públicos ${ }^{78}$. Las críticas de Miguel de Cesena, igual que las de Ockham, fundamentales para comprender el nuevo espacio político que se abría, iban dirigidas de lleno a la plenitudo potestatis pontificia y a la línea de flotación de la autoridad papal definiendo una Iglesia a la que se sustrae ya la influencia sobre poder civil. Como analizaba en su día August Fink la crítica radical de los disidentes franciscanos a la plenitudo potestatis define una imagen de la Iglesia que en absoluto busca el gobierno y dominio del espacio civil sino que debe adaptarse a estas nuevas formas estatales emancipadas de su tutela ${ }^{79}$.

${ }^{74}$ ACS, S1/5.

75 Ibidem.

${ }^{76}$ García de Cortázar 2002, p. 85.

77 "Desde una perspectiva descriptiva los hechos eran así, esto es, una conflictividad cada vez más fuerte entre una concepción teológica hegemónica del mundo y un nuevo espíritu que anticipa principios y argumentos de la Edad Moderna, como serían la autonomía de la razón frente a la fe y la separación del poder religioso y el poder laico". López 2012, p. 266.

${ }^{78}$ ASV, Reg. Vat. 115, ff. 198-199. Edita parcialmente esta comunicación Riezler 1891, doc. 1248 , pp. $436-437$.

${ }^{79}$ Fink 1998, p. 113. Cf. Fink 1981. En cuanto a Okham desde 1328 "redigiu o An princeps. De seus treze capítulos, os seis primeiros destinavam-se a negar a plenitudo potestatis ao papa, refutando as teses curialistas -apoiando-se, para tanto, na liberdade evangélica e na preeminência do imperador-, tema recorrente em toda a sua obra política". Tavares 2008, p. 230. Ana Paula Tavares desarrolla aquí un profundo análisis de la obra de Ockham en la línea relacionada con el pensamiento político y las formulaciones de crítica al pontificado. 
Nuevos tiempos y primeras formulaciones políticas para los futuros estados modernos con teorizaciones amparadas y protegidas por el Imperio ${ }^{80}$. De todo ello informaba el pontífice al prelado de Santiago: ut de rumoribus partium Italie, qui occurrunt presencialiter in curia, noticiam habeas pleniorem, ecce quod illos tibi succinte notificandos providimus per presentes ${ }^{81}$.

Irrumpe así en este espacio del noroeste peninsular no sólo la crítica política sino la persecución de Juan XXII a las teorías más radicales acerca de la pobreza (que implican cruda crítica a la jerarquía y pontificado) emanadas de los franciscanos y materializadas en los espirituales en este primer tercio del siglo XIV; un proceso que tiene mucho que ver en la defensa del papa del espacio económico de la Iglesia en el marco de toda su reforma administrativa y económica ${ }^{82}$. Nuevamente es preciso aludir al contexto. Las teorías de Guillermo de Ockham y de los espirituales, enormemente críticos con la autoridad pontificia que se intentaba mantener fuerte, encontraron su apoyo en la figura de Luis de Baviera y su antipapa Nicolás $\mathrm{V}^{83}$, franciscano. No solamente eso sino que, como hemos visto, autores como Marsilio de Padua y Jean Jandun, alineados igualmente con el bávaro ${ }^{84}$, comenzaron a desarrollar las nuevas teorías de crítica al poder pontificio, base para el conciliarismo de la centuria siguiente ${ }^{85}$, y de refuerzo del

${ }^{80}$ Clara es la influencia de Miguel de Cesena, por ejemplo, en el decreto Cunctos populos de 1328. Souza, J.A. 2016, pp. 335-336.

${ }^{81}$ Riezler 1891, p. 436.

${ }^{82}$ Destaca Maria Armênia de Souza "su voluntad de proteger el orden económico de la Iglesia, que le acabará enfrentando con los franciscanos y convirtiendo en doctrina oficial la filosofía de la propiedad de Tomás de Aquino". Souza 2016, p. 256.

83 "Ockham fue acusado de herejía por nominalista. El canciller de la Universidad de Oxford John Lutetrell lo acusó ante Avignon a donde fue llamado y de 51 artículos de sus doctrinas fueron sometidos a juicio 23. Durante esa estancia surgió el conflicto entre Juan XXII y Luis de Baviera al cuestionarse el poder absoluto del Papa. Ockham se puso de lado del rey bávaro y empezó su enfrentamiento con el Papa desde una filosofía política que contenía elementos teológicos que le llevaron incluso a condenar a Juan XXII por hereje por sus doctrinas políticas. Política y teología entran en una dialéctica poco común para aquellos tiempos". López 2012, p. 269. "É justamente no cruzamento da questão da pobreza com a causa de Luís da Baviera que se encontra o eixo da polêmica desenvolvida por Ockham ao longo de seus vários tratados". Tavares 2008 , nt. 31 p. 251.

${ }^{84}$ Refleja García de Cortázar la existencia de esta suerte de bando opuesto al poder pontificio en el marco de la propia coyuntura aunque temporal: "de momento, una reacción muy humana colocó a los críticos del papado (espirituales franciscanos, Miguel de Cesena, Marsilio de Padua, Guillermo de Ockham) al lado de las pretensiones «ilusas y veleidosas» de su enemigo, el emperador Luis de Baviera. La aventura romana de este (con su coronación imperial laica y el nombramiento de un antipapa) acabó años después en la derrota y la desilusión de sus seguidores"; vendrá luego Carlos IV y su Bula de Oro intentando corregir la situación. García 2010 , 409. En cuanto a Marsilio de Padua y el espacio político que sugiere en oposición al pontificado cf. Godthart 2014.

${ }^{85}$ El marco conciliar y su desarrollo tanto en el momento del denominado conciliarismo como en las raíces anteriores, tiene amplio tratamiento en la historiografía europea, e igualmente en su desarrollo factual y en el teórico. No es este un trabajo de corte teológico pero es 
poder estatal en el marco de la incipiente evolución de los estados ${ }^{86}$. El Defensor pacis es perfecta muestra de la línea de pensamiento, que podemos resumir con las palabras de Jean Chièlini perfectamente ilustrativas de dos espacios, bandos y concepciones: le "Defensor pacis" est l'anti "Unam Sanctam" ${ }^{87}$. Frente a ellos otras figuras destacadas del pensamiento en la primera mitad del siglo XIV se alinearon con el poder papal y Juan XXII, caso de Agustín Trionfo y, especialmente, Álvaro Pais, o Pelagio, de origen gallego. Éste, en su obra De Statu et planctu Ecclesie, confiere nuevos planteamientos acerca del poder pontificio y manteniendo defensa de la plenitudo potestatis ${ }^{88}$, y en su Speculum regis desarrolla la crítica a la tiranía ejercida desde la monarquía, en un conjunto de reflexiones dedicado a Alfonso XI ${ }^{89}$, de la misma manera que en 1337 dirige dos misivas de matiz marcadamente político al rey de Portugal Alfonso IV ${ }^{90}$. Puntualiza García de Cortázar que no resulta algo particular de este momento, sino que a lo largo de todo el período siempre había habido en la cristiandad alguna voz solitaria o colectiva que clamaba en defensa de una aspiración semejante en cuanto a la sustracción eclesiástica de competencias seculares ${ }^{91}$.

Cesa aquí la documentación a Compostela, sin que quedase en los archivos y fuentes consultados vestigio alguno de ulteriores comunicaciones entre la sede de Aviñón y la iglesia de Santiago sobre el particular. El conflicto

menester referir como fundamento historiográfico inicial de manera global la panorámica que ofrece Aldo Landi $c f$. Landi 2001, y la profundización de Schatz en la linealidad de la evolución primacial pontificia en Schaltz 1996, pp. 149-160. Además $c f$. Landi 1985, Brandmüller 1990, Oakley 2003, Girgensohn 2007, Brandmüller 2009. Y ya en el más amplio espectro y con una vertiente teológica más marcada $c f$. Schneider 1976.

86 "Tra i fautori di Ludovico il Bavaro va ricordato invece anzitutto Marsilio da Padova, l'autore del Defensor pacis, opera in cui si esaltarono i diritti dello Stato, si criticò il criterio secondo cui il papa, per reperire risorse, moltiplicò l'imposizione di decime, all'inizio pagate per organizzare la crociata e poi mantenute per il finanziamento della política generale del papato, e, all'interno della Chiesa, si cominciò a far strada il concetto de lla superiorità del Concilio sul pontefice. Sui princìpi di affermazione dello Stato nazionale si soffermarono por Pietro di Blois, Pierre Flotte e Guglielmo di Nogaret”. Gatto 2001, p. 109.

${ }^{87}$ Chélini 2006, p. 491.

${ }^{88}$ Interesante el papel de Álvaro Pais, al que, en un inicio, como señala Francisco Javier Rojo Alique, se le consideraba en el bando imperial y apoyando al antipapa Nicolás V, quizá por el apoyo de Álvaro a los espirituales mientras estuvieron bajo la obediencia pontificia. Confía en él, a pesar de todo, Juan XXII, que lo nombra penitenciario en 1329-1330, destacando como autor de importantes tratados políticos. Rojo 2014, p. 315. Una visión contrapuesta de ambas formulaciones, la de Álvaro Pais y Marsilio de Padua, nos la ofrece Gayoso 2006, pp. 11-28.

${ }^{89}$ Una pincelada la que ofrece Javier Fernández Conde en Fernández 2011, pp. 123-124.

${ }^{90}$ José Antônio de C.R. de Souza plantea una visión completa de este contenido en su perspectiva Souza 2003, pp. 51-67.

${ }^{91}$ Algo que remonta incluso a la recepción de la Política de Aristóteles, y al hecho de que "el propio Tomás de Aquino había sido, en el fondo, un paladín de la aparición del Estado como entidad autónoma capaz de canalizar las pretensiones de los hombres que, como animales políticos, aspiraban a vivir en comunidad y a elaborar sus propias leyes en la polis". García de Cortázar 2012, p. 407. 
mantuvo su desarrollo hasta adentrarse en la segunda mitad del siglo XIV más allá del fallecimiento de Luis de Baviera, en 1347, y pasó por diversas fases. El sucesor de Juan XXII, Benedicto XII, sostuvo una postura mucho más flexible en relación con el Rey de Romanos pero con Clemente VI se vuelve al enconamiento de la disputa a pesar de que la situación se relaja con la declaración del nuevo Rey, Carlos $\mathrm{IV}^{92}$, renunciando a intervenir en Italia ${ }^{93}$. Georg Strak ha realizado recientemente una profundización en los pronunciamientos de este último pontífice atacando todavía a Luis de Baviera desde un primer sermón en 10 de octubre de $1343^{94}$, pero ya nada se refleja en los archivos compostelanos.

Las comisiones a Santiago de Compostela remitidas en el año 1324, con el fin, al igual que en el resto de Europa, de difundir las acciones pontificias contra Luis de Baviera constituyen un episodio más en el enfrentamiento global mantenido por los dos principales poderes del mundo medieval: Pontificado e Imperio. La iglesia de Santiago se constituye y concibe aquí como brazo ejecutor, en su provincia y/o reino, de las decisiones pontificias, sobre la base de un prelado de gran confianza para Juan XXII como era Berenguel de Landoira y plasmando en buena medida la centralización de poder eclesiástico que se desarrollaba ya desde inicios del siglo XIII en cuanto a la auctoritas pontificia e intensificada ahora partiendo de Aviñón. Podemos intuir cumplida consecuencia de estas comunicaciones en el concilio provincial de noviembre de 1324 jugando su papel junto con el contexto relativamente reciente de la revuelta de 1318-20 que ponía de igual manera a los poderes temporal y espiritual frente a frente.

El enfrentamiento que mantenía el poder pontificio con Luis de Baviera y los Visconti de Milán no tuvo únicamente implicaciones en su inmediato entorno geopolítico y cronológico sino que, de cara al futuro, puso alguna de las bases sobre las que se desarrollaría la principal confrontación

\footnotetext{
${ }^{92}$ Clemente VI era uno de los que había promovido a Carlos IV al trono, tras seguir los pasos de Juan XXII y excomulgar y deponer a Luis de Baviera. Álvarez 1982, p. 34. La atención sobre su relación con Luis de Baviera viene ya de antiguo. A modo de ejemplo $c f$. Weech 1864. Para aportación más reciente $c f$. Heinz 2002.

${ }^{93}$ Evidentemente, el proceso de recolocación de poderes continúa inexorable ya, en un fluir hacia la Europa de la Modernidad. De hecho, no mucho después "Italia se sitúa también en el primer plano de las preocupaciones de Clemente VI: la deposición de Luis de Baviera, la situación de Sicilia bajo la reina Juana I, la sublevación romana bajo la dirección de Colà di Rienzo, la pugna con Giovanni Visconti por el control de Bolonia, y la constitución de señorías independientes en los Estados de la Iglesia, son motivos suficientes para que se vuelva a una intervención armada en Italia de la intensidad de época de Juan XXII". Álvarez 1999, p. 14.

${ }^{94}$ Strak 2014, pp. 420 ss. De manera anterior hay buena aproximación a la relación de este pontífice con el emperador en la aportación de Heinz Thomas "Clemens VI. und Ludwig der Bayer", en Nehlsen, Herman 2002, pp. 75-117.
} 
eclesiástica bajomedieval: el Cisma de Occidente ${ }^{95}$. Una pugna en la cual Compostela volvió a estar presente y tomar partido ${ }^{96}$ y en la que se recogería parte de lo sembrado en este lejano 1324.

\section{APÉNDICE DOCUMENTAL}

1324, julio, 15. Aviñón.

Litteræ executoriæ de Juan XXII al arzobispo de Santiago, Berenguel de Landoira, por las que dispone la reunión de los obispos, abades, eclesiásticos y cabildos de Galicia, en fecha a convenir, para leer los procesos que la Curia romana había emitido contra los hijos de Mateo Visconti de Milán, declarándolos herejes, y publicando conjuntamente el jubileo con las indulgencias de los Santos Lugares en Jerusalén para que rueguen por la conservación de la fe católica. pendiente.

A.- ACS, S1/4. Original. Pergamino. 395x540 mm. Sello plomado

R.- ASV, Reg. Vat. 112, f. 57.

R.- ACS, IG 363, Relación de "Bulas y breves sueltos en una caja”, hecha aquella en el $1665, \mathrm{n}^{\circ} 15$.

Regestado en: Riezler 1891, doc. 376. Sánchez 2007, doc. 48, p. 26.

Iohannes episcopus, seruus seruorum Dei, venerabili fratri Berengario, archiepiscopo Compostellano, salutem et apostolicam benedictionem.

Quam grauiter et iniuriose dampnati / heretici Galeatius ${ }^{97}$, Marchus ${ }^{98}$, Luchinus $^{99}$, Iohannes ${ }^{100}$ et Stephanus ${ }^{101}$, nati dampnate memorie quondam Mathei ${ }^{102}$ de vicecomitibus heretici de Mediolano, necnon Raynal/ dus ${ }^{103}$

\footnotetext{
${ }^{95}$ Con el regreso de la sede pontificia de Aviñón a Roma se hizo más necesaria la pacificación de Italia y con ella del entorno romano; para ello se crea una liga de paz, integrada por el propio papado y las ciudades de Florencia, Siena, Nápoles, Pisa, Arezzo y Cortona. La orientación de esta liga fue precisamente la oposición al expansionismo de los Visconti, el cual se mantuvo hasta el estallido del Cisma. Álvarez 1982, p. 37.

${ }^{96}$ Sánchez 2013b.

${ }^{97}$ Galeazzo I Visconti (1277-1328), señor de Milán en 1322-1327.

${ }^{98}$ Marco Visconti, Balatrone (hacia 1280-1329).

${ }^{99}$ Luchino Visconti (1287/92-1349), señor de Milán en 1339-1349.

${ }^{100}$ Giovanni Visconti (hacia 1290-1354), arzobispo y señor de Milán desde 1341 junto con su hermano Luchino.

${ }^{101}$ Setfano Visconti $(\dagger 1327)$, señor de Arona.

${ }^{102}$ Mateo I Visconti, el Grande (1250-1322).

${ }^{103}$ Rinaldo d'Este, señor de Ferrara con su hermano Obizzo III.
} 
et Opizo $^{104}$, quondam marchiones Eisteoses a suis competentibus iudicibus de here[si sententia]liter et publice condempnati, eorumque complice[s] et fautores ad / confusionem et exterminium liberta[tis] ecclesiastice et subuersionem fidei catholice nequiter aspirantes Deum, nos et Romanam Ecclesiam [ma]trem fidelium / offenderint hactenus et incessanter offendant eiusque nostra usurpauerint indebite et usurpent euidencia facti notoriat, ac diuersorum processuum tam per / nos quam per dilectos filios [..] inquisitores heretice prauitatis et alios auctoritate apostolica dudum habitorum contra eos series manifestat. Verum / cum nos ad hereticorum predictorum, ac complicum et fautorum suorum, conferendam superbiam que aduersus Deum et ipsam Ecclesiam suosque fideles / blasfemiis, uiolenciis, sceleribus et enormibus excessibus ac iniuriis atrocibus solito durius intumescit nuper de fratrum nostrorum consilio per / uictricis crucis suffragium prouiderimus exurgendum omnibus uere penitentibus et confessis, eosdem hereticos ac complices, fautores, adiutores, con/ siliatores et eis adherentes impugnantibus, seu de bonis suis ad impugnationem eorum congrue ministrantibus certas remissiones et indul/ gencias que consueuerunt elargiri per Sedem Apostolicam transfretantibus in Terre Sancte, subsidium concedendo sicut in processibus nostris factis su/ per hoc plenius continetur.

Nos, premissa uolentes, ad venerabilium fratrum nostrorum episcoporum ac dilectorum filiorum electorum, abbatum, priorum, I decanorum, prepositorum, capitulorum et conuentuum aliarumque personarum ecclesiasticarum, regularium et secularium, exemptarum et non exemptarum, illarum / partium aliorumque fidelium deduci [n]oticiam ut ad compassionem eiusdem Ecclesie, matris sue, ac defensionem fidei orthodoxe, predictasque $\mathrm{re} /$ missiones et indulgentias acquirenda[s] promptius et deuotius animentur, fraternitati tue per apostolica scripta mandamus quatinus predictos / episcopos, electos, abbates, priores, decan[os], prepositos, capitula, conuentus et alias personas ecclesiasticas totius regni Galecie quamuis de tua / non sint prouincia necnon tu[o]rum ciuitatis, diocesis et prouincie que tamen de regno Portugalie non existant, de quibus tibi / uidebitur expedire ad [cert]os [diem] et locum, auctoritate nostra comictare procures processus nostros, presertim dictas remissiones et / indulgencias et alia contenta in eis publicaturus solenniter ac iniurias, excessus, contumelias et [h]orrenda scelera per eosdem hereticos / eorumque complices, fautores et ualit[o]res comissa nequiter, et que horribiliter et contra Deum et eandem Ecclesiam incessanter comittere / non uerentur necnon et alia que cirta premissa expedire tue prudencie uidebuntur uerbo predicationis et aliis exhortationibus sa/ lubribus ostensurus.

${ }^{104}$ Obizzo III d'Este (1294-1352), marqués de Ferrara desde 1317. 
Datum Auinione, idus iulii, pontificatus nostri anno octauo.

(Sello plomado: (anv) Ioha/ nnes / pape: XXII. (rev) Sanctus Paulus, Sanctus Petrus).

\section{BIBLIOGRAFÍA CITADA}

Acht, Peter; Menzel, Michael (eds.) (1991-2018), Regesten Kaiser Ludwigs des Bayern (1314-1347). Nach Archiven und Bibliotheken geordnet, 11 vols., Colonia, Böhlau Verlag.

Álvarez Palenzuela, Vicente Ángel (1982), El Cisma de Occidente, Madrid, Rialp.

Álvarez Palenzuela, Vicente (1999), La crisis de la monarquía papal y el conciliarismo en el trascurso del Trescientos al Cuatrocientos, "Cuadernos de Historia Medieval" 2, pp. 3-27.

Bauer, Jörg. (2005), Der Kampf Ludwigs des Bayern mit dem Papsttum: die Nichtauswirkung des Interdikts auf die Reichsstadt Esslingen, en Litz, Gudrun; Munzert, Heidrun; Liebenberg, Roland (eds.), Frömmigkeit - Theologie - Frömmigkeitstheologie. Contributions to European Church History. Festschrift Berndt Hamm, Leiden, Brill, pp. 81-88.

Berg, Martin (1987), Der Italienzug Ludwigs des Bayern. Das Itinerar der Jahre 1327-1330, "Quellen und Forschungen aus Italienischen Archiven und Bibliotheken” 67, pp. 142-197.

Bertelloni, Francisco (2006), La crisis de la monarquía papal mediante un modelo causal ascendente: Juan de París, De regia potestate et papali, "Veritas" 51/3, pp. 51-66.

Black, Jane (2009), Absolutism in Renaissance Milan. Plenitude of Power Under the Visconti and the Sforza 1329-1535, Nueva York, Oxford University Press.

Böttcher, Diethelm (2010), Johannes XXII. Ludwig der Bayer und die monitio canonica, "Zeitschrift der Savigny-Stiftung für Rechtsgeschichte.: Kanonistische Abteilung" 127, pp. 314-349.

Brandmüller, Walter (1990), Sacrosancta synodus universalem repraesentans ecclesiam: Das Konzil als Repräsentation der Kirche, en Brandmüller, Walter, Papst und Konzil im Großen Schisma, Paderborn, Múnich, Schöningh, pp. 157-170

Brandmüller, Walter (2009), Zum Problem der Ökumenizität von Konzilien, "Annuarium Historiae Conciliorum" 41, pp. 275-312.

Büttner, Andreas (2011), Die Doppelwahl und -krönung von 1314: Ludwig von Bayern und Friedrich von Österreich, en Büttner, Andreas, Der Weg zur Krone: Rituale der Herrschererhebung im römisch- 
deutschen Reich des Spätmittelalters, Ostfildern, Thorbecke, vol. 1, pp. 294-338.

Cabezuelo Pliego, José Vicente (2006), Diplomacia y guerra en el Mediterráneo medieval. La liga véneto-aragonesa contra Génova de 1351, "Anuario de Estudios Medievales" 36/1, pp. 253-294.

Cariboni, Guido (2008), Comunicazione simbolica e identità cittadina a Milano presso i primi Visconti (1277-1354), "Reti Medievali Rivista" 9/1, pp. 1-50.

Cavero Domínguez, Gregoria; Álvarez Álvarez, César; Martín Fuertes, José Antonio (2001), Colección documental del Archivo Diocesano de Astorga, León, Centro de Estudios e Investigación San Isidoro.

Cerdá y Rico, Francisco (ed.) (1787), Cronica de D. Alfonso el Onceno de este nombre, de los reyes que raynaron en Castilla y en Leon, t. I, Madrid, Impr. Antonio de la Sancha.

Chélini, Jean (2006), Histoire religieuse de l'Occiedent médiéval, París, Hachette Pluriel.

Díaz y Díaz, Manuel Cecilio (ed.) (1983), Hechos de don Berenguel de Landoria, arzobispo de Santiago. Introducción, edición crítica y traducción, Santiago de Compostela, Universidade de Santiago de Compostela.

Eckhardt, Wilhelm Alfred (2007), Kaiser Ludwig der Bayer und das Stadtrecht für Schweinsberg, "Zeitschrift des Vereins für Hessische Geschichte und Landeskunde" 112, pp. 51-56.

Eisenzimmer, Mirjam (2011), Marquard von Randeck (1296-1381): Ein Redner für Ludwig den Bayern an der Kurie, en Rhetorik in Mittelalter und Renaissance. Konzepte - Praxis - Diversität, Múnich, Herbert Utz Verlag, pp. 267-289.

Felten, Franz J. (1998), Kommunikation zwischen Kaiser und Kurie unter Ludwig dem Bayern (1314-1347). Zur Problematik der Quellen im Spannungsfeld von Schriftlichkeit und Mündlichkeit, en Heimann, Heinz-Dieter; Hlavácek, Ivan (eds.), Kommunikationspraxis und Korrespondenzwesen im Mittelalter und in der Renaissance, Paderborn, Ferdinand Shöningh, pp. 51-89

Fernández Catón, José María (1978-2006), Catálogo del Archivo Histórico Diocesano de León, 4 vols., León, Centro de Estudios e Investigación San Isidoro.

Fernández Conde, Javier (2011), La religiosidad medieval en España. Baja Edad Media (siglos XIV-XV), Gijón, Ediciones Trea.

Filippini, Ambrogio (2014), I Visconti di Milano nei secoli XI e XII. Indagini tra le fonti, Trento, Edizioni Tangram.

Fink, Karl A. (1981), Papsttum und Kirche im abendländischen Mittelalter, Múnich, C.H. Beck Verlag. 
Frink, Karl August (1998), Chiesa e papato nel Medioevo, Bolonia, Il Mulino. García de Cortázar, José Ángel (2012), Historia religiosa del Occidente medieval (Años 313-1464), Madrid, Editorial Akal.

García Oro, José (coord.) (2002), La diócesis de Compostela en el régimen de cristiandad (1100-1550). De Gelmírez a Fonseca, en Historia de las diócesis españolas. Santiago de Compostela. Tuy-Vigo, Madrid, Biblioteca de Autores Cristianos.

Gatto, Ludovico (2001), Storia della Chiesa nel Medioevo, Roma, Newton Compton.

Gayoso, Andrea (2006), Doctrina jurídica del poder en la Edad Media: Álvaro Pelayo ante Santiago de Viterbo y Marsilio de Padua, "Revista de la Facultad de Derecho" 25, pp. 9-28.

Girgensohn, Dieter (2007), Von der konziliaren Theorie des späteren Mittelalters zur Praxis: Pisa 1409, en Müller, Heribert; Helmrath, Johannes (eds.), Die Konzilien von Pisa (1409), Konstanz (1414-1418) und Basel (1431-144). Institutionen und Personen, Stuttgart, Jan Thorbecke, pp. 61-94.

Godthardt, Frank. (2014), Marsilius von Padua als politische Herausforderung für Johannes XXII, en Schmidt, Hans-Joachim; Rohde, Martin (eds.), Papst Johannes XXII. Konzepte und Verfahren seines Pontifikats, Berlín, De Gruyter, pp. 75-118.

Goñi Gaztambide, José (1965), Catálogo del Archivo Catedral de Pamplona: tomo I (829-1500), Pamplona, Diputación Foral de Navarra - Institución Príncipe de Viana.

Heinz, Thomas (2002), Clemens VI. und Ludwig der Bayer, en Nehlsen, Hermann; Hermann, Hans-Georg (eds.), Kaiser Ludwig der Bayer. Konflikte, Weichenstellungen und Wahrnehmung seiner Herrschaft, Paderborn, Múnich, Ferdinand Shöningh, pp. 75-117.

Justo Fernández, Jaime (2001), Los concilios compostelanos medievales (1120-1563). Edición crítica, "Annuarium Historiae Conciliorum" 33/2, pp. 309-404.

Landi, Aldo (1985), Il Papa deposto (Pisa 1409): l'idea conciliare nel Grande Scisma, Turín, Claudiana.

Landi, Aldo (2001), Le radici del conciliarismo. Una storia della canonistica medievale alla luce dello sviluppo del primato del Papa, Turín, Claudiana.

Liere, Frans van (2001), Witchcraft as Political Tool? John XXII, Hugues Géraud, and Mateo Visconti, "Medieval Perspectives" 16, pp. 165-173.

López Alsina, Fernando (2011), Los Tumbos de Santiago de Compostela y las relaciones con el Pontificado, en Herbers, Klaus; Fleisch, Ingo 
(coords.) (2001), Erinnerung - Niederschrift - Nutzung: Das Papsttum und die Schriftlichkeit im mittelalterlichen Westeuropa, Berlín, Walter De Gruyter, pp. 137-170.

López Calera, Nicolás (2012), Guillermo de Ockham y el nacimiento del laicismo moderno, "Anales de la Cátedra Francisco Suárez" 46, pp. 263-280.

López Ferreiro, Antonio (1903), Historia de la Santa A.M. Iglesia de Santiago de Compostela, t. VI, Santiago de Compostela, Impr. y Exc. del Seminario Conciliar Central.

Lortz, Joseph (2003), Historia de la Iglesia en la perspectiva de la Historia del Pensamiento. Tomo I: Antigüedad y Edad Media, Madrid, Ediciones Cristiandad.

Majocci, Piero (2010), The Treasure of Theodelinda: Ideological Claims and Political Contingencies in the Construction of a Myth, "Forschungen zur Geschichte des Mittelalters" 17, pp. 245-268.

Marín Moreno, José Luis (2005), Conciliarismo y escepticismo. La crisis del pontificado en los siglos XIV y XV, "Daimon. Revista Internacional de Filosofía” 36, pp. 53-64.

Menzel, Michael (2001), Ludwig der Bayer. Der letzte Kampf zwischen Kaisertum und Papsttum, en Schmid, Alois (ed.), Die Herrscher Bayerns, Múnich, CH Beck Verlag, pp. 106-117.

Menzel, Michael (2015-2016), Am Ende des Reiches. Aachen, Ludwig IV. und die Wahlmonarchie, "Zeitschrift des Aachener Geschichtsvereins" 117-118, pp. 43-74.

Miethke, Jürgen (2002), Der Kampf Ludwigs des Bayern mit Papst und avignonesischer Kurie in seiner Bedeutung für die deutsche Geschichte, en Nehlsen, Hermann; Hermann, Hans-Georg (eds.), Kaiser Ludwig der Bayer. Konflikte, Weichenstellungen und Wahrnehmung seiner Herrschaft, Paderborn, Múnich, Ferdinand Shöningh, pp. 39-73.

Mollat, Michel; Vauchez, André (eds.) (1990), Histoire du christianisme: des origines à nos jours. Vol. 6, Un temps d'épreuves: 1274-1449, París, Desclée - Fayard.

Monti, Carla Maria (2016), L'epistola come strumento di propaganda politica nella cancelleria di Gian Galeazzo Visconti, "Mélanges de l’École française de Rome" 128/1, pp. 7-25.

Monumenta Germanice Historica, sec. VI, t. V, Hanoveræ et Lipsiæ, 19091913.

Nehlsen, Hermann; Hermann, Hans-Georg (eds.) (2002), Kaiser Ludwig der Bayer. Konflikte, Weichenstellungen und Wahrnehmung seiner Herrschaft, Paderborn, Múnich, Ferdinand Shöningh. 
Novás Pérez, M. ${ }^{a}$ Elena (2008), Catálogo da Colección Guerra Campos do Arquivo-Biblioteca da Catedral de Santiago de Compostela, A Coruña, Consello da Cultura Galega.

Oakley, Francis (2003), The Conciliarist Tradition: Constitutionalism in the Catholic Church, Oxford, Oxford University Press.

Patera, Eugen (1992), Die Schlacht bei Mühldorf von 1322 in einer böhmischen Quelle, "Das Mühlrad" 34, pp. 5-16.

Portela Silva, María José (2007), Documentos da Catedral de Lugo. Século XIV (volume I), Pontevedra, Consello da Cultura Galega.

Portela, Ermelindo; Pallares, M. ${ }^{\mathrm{a}}$ Carmen (2000), De Gelmírez a los irmandiños. Conflictos sociales en la ciudad de Santiago, en Estepa Díez, Carlos; Martínez Sopena, Pascual; Jular Pérez-Alfaro, Cristina, El Camino de Santiago: estudios sobre peregrinación y sociedad, Madrid, Fundación de Investigaciones Marxistas.

Riezler, Sigmund von (1891), Vatikanische Akten zur deutschen Geschichte in der Zeil Kaiser Ludwigs des Bayern, Innsbruck, Verlag der Wagnerschen Universitats-Buchhandlung.

Rodríguez-Picavea, Enrique (2010), Diplomacia, propaganda y guerra santa en el siglo XIV: la embajada castellana a Aviñón y la elaboración del discurso ideológico, "Anuario de Estudios Medievales" 40/2,pp. 765-789.

Rojo Alique, Francisco Javier (2014), Intelectuales franciscanos y monarquía en la Castilla medieval, "Sémata. Ciencias Sociais e Humanidades" 26, pp. 297-318.

Rucquoi, Adeline (1991), El cardenal legado Guillaume Peyre de Godin, en García y García, Antonio (ed.), Estudios Jurídico-canónicos Conmemorativos del Primer Cincuentenario de la restauración de la Facultad de Derecho Canónico en Salamanca (1940-1989), Salamanca, Universidad Pontificia, pp. 99-122.

Sáez, Emilio et al. (1995), Colección documental del archivo de la Catedral de León, vol. 11, León, Centro de Estudios e Investigación San Isidoro.

Sánchez Sánchez, Xosé M. (2007), Regesta compostelana del pontífice Juan XXII (1316-1334), "Archivum Historiae Pontificiae" 45, pp. 9-37.

Sánchez Sánchez, Xosé M. (2008), La intervención del poder pontificio en la revuelta de 1318-1320 en territorio compostelano. Juan XXII y Berenguel de Landoira, "Territorio, Sociedad y Poder" 3, pp. 195-208.

Sánchez Sánchez, Xosé M. (2010), Le pouvoir et les nominations épiscopales au siège de Saint-Jacques de Compostelle. La nomination de Bérenguer de Landorre, par Jean XXII (1317), "Compostelle. Cahiers d'Études de Recherche et d'Histoire Compostellanes" 13, pp. 32-46. 
Sánchez Sánchez, Xosé M. (2013a), La documentación pontificia de la Iglesia de Santiago de Compostela en la Edad Media. Un proyecto de colección documental, "Memoria Ecclesiæ" 37, pp. 295-306.

Sánchez Sánchez, Xosé M. (2013b), La iglesia de Santiago de Compostela y el pontificado en la Edad Media (1140-1417), A Coruña, Universidade de Santiago de Compostela - Consorcio de Santiago.

Sánchez Sánchez, Xosé M.; Novás Pérez, M. ${ }^{a}$ Elena (2013), Catálogo de las Colecciones López Ferreiro y Guerra Campos del Archivo de la Catedral de Santiago, A Coruña, Cabildo de la Catedral de Santiago.

Schatz, Klaus (1996), El primado del papa. Su historia desde los orígenes hasta nuestros días, Santander, Sal Terrae.

Schneider, Hans (1976), Der Konziliarismus als Problem der neueren katholischen Theologie. Die Geschichte der Auslegung der Konstanzer Dekrete von Febronius bis zur Gegenwart, Berlín, Walter De Gruyter.

Schneidmüller, Bernd (2013), Kaiser Ludwig IV. Imperiale Herrschaft und reichsfürstlicher Konsens, "Zeitschrift für historische Forschung" 40, pp. 369-392.

Schneidmüller, Bernd (2014), Wir sind KaiserLudwig IV. zwischen Gott und den Fürsten, en Peter, Wolf; Brockhoff, Evamaria, Ludwig der Bayer Wir sind Kaiser!. Bayerisches Staatsministerium für Bildung und Kultus, Wiss. und Kunst, Haus der Bayerischen Geschichte, Augsburgo, Haus der Bayerischen Geschichte, pp. 27-32.

Seibert, Hubertus (ed.) (2014), Ludwig der Bayer (1314-1347). Reich und Herrschaft im Wandel, Ratisbona, Schnell \& Steiner.

Souza, Armênia María de (2016), El pontificado de Juan XXII (1316-1334), en Bayona Aznar, Bernardo; Souza, José Antônio de Camargo Rodrigues de (coords.), Iglesia y Estado. Teorías políticas y relaciones de poder en tiempo de Bonifacio VIII (1294-1303) y Juan XXII (13161334), Zaragoza, Prensas de la Universidad de Zaragoza.

Souza, José Antônio de Camargo Rodrigues de (2003), D. Álvaro Pelayo O. Min. y D. Alfonso IV de Portugal y las relaciones de Poder, "Anales del Seminario de Historia de la Filosofía” 20, pp. 51-67.

Souza, José Antônio de Camargo Rodrigues de (2016), Luis de Baviera de Wittelsbach y el decreto de deposición del papa Juan XXII Cunctos populos, en Bayona Aznar, Bernardo; Souza, José Antônio de Camargo Rodrigues de (coords.), Iglesia y Estado. Teorías políticas y relaciones de poder en tiempo de Bonifacio VIII y Juan XXII, Zaragoza, Prensas de la Universidad de Zaragoza.

Strak, Georg (2014), Doppelzüngige Phrasendrescherei? Die Konsistorialansprachen Papst Clemens VI. gegen Ludwig den Bayern, en Sei- 
bert, Hubertus (ed.), Ludwig der Bayer (1314-1347). Reich und Herrschaft im Wandel, Ratisbona, Schnell \& Steiner, pp. 413-433.

Tavares Magalhães, Ana Paula (2008), O papado avinhonense e os poderes civis: as décadas de 30 e de 40 do século XIV a partir de três obras de Guilherme de Ockham, "História" 27/2, pp. 223-251.

Ullman, Walter (1999), Il papato nel Medioevo, Bari, Laterza.

Vasconcelos, Maria da Assunção Jácome de; Sousa Araújo, Antonio de (1986), Bulário bracarense, Braga, Arquivo Distrital de Braga.

Vicario Santamaría, Matías (dir.) (1998), Catálogo del Archivo Catedralicio de la Catedral de Burgos, vols. 1-2, Burgos, Caja de Ahorros del Círculo Católico.

Weech, Friedrich von (1864),, Kaiser Ludwig der Bayer und Papst Clemens VI, "Historische Zeitschrift" 12/2, pp. 315-346.

Wilhelm, Bruno (1927), Die Verhandlungen Ludwigs des Bayern mit Friedrich von Österreich in den Jahren 1325-1326 und die deutsche Erzählung über den „Streit zu Mühldorf“, "Mitteilungen des Instituts für Österreichische Geschichtsforschung" 42, p. 23-63.

Fecha de recepción del artículo: noviembre 2017

Fecha de aceptación y versión final: noviembre 2018 